\title{
IMOBILIZAÇÃO DE FRATURAS DISTAIS DO ÚMERO EM CÃES ATRAVÉS DE TRANSFIXAÇÃO ÓSSEA
}

\author{
IMOBILIZATION OF DISTAL HUMERAL FRACTURES IN DOGS \\ WITH EXTERNAL SKELETAL FIXATION
}

\section{Isabela Schmitt*}

\section{RESUMO}

Fraturas distais do úmero, em cinco cães, foram imobilizadas através de transfixação esquelética com pinos de Steinmann estabilizados com barras de acrílico autopolimerizável. $O$ artifício foi adaptado no sentido craneo-caudal com imobilização do cotovelo. Três dos cães apresentaram fratura unilateral, outro bilateral e o quinto unilateral com osteomielite. A metodologia adotada permitiu rápida recuperação dos pacientes sendo indicado como opção eficiente e de baixo custo.

Palavras-chave: fratura, úmero, cão, transfixação óssea

\section{SUMMARY}

Distal humeral fractures were immobilized in five dogs by skeletal transfixation with Steinmann pins and stabilized with autopolimerizing acrilic. The devices were adapted in a craneo-caudal way with immobilization of the elbow. Fractures were unilateral in three dogs, bilateral in an other and unilateral with infection in the other one. The methodology utilized offered appropriate recovery of the dogs. The technique may be indicated as effective option and low cost.

Key words: fracture, humerus, dogs; skeletal transfixation

\section{INTRODUÇÃO}

As fraturas de úmero não são comuns na rotina veterinária. $\mathrm{Na}$ maioria das vêzes atingem os terços médio e distal do osso com cavalgamento dos segmentos, principalmente naquelas oblíquas e espirais (BRINKER et al, 1986).

\author{
Alceu Gaspar Raiser**
}

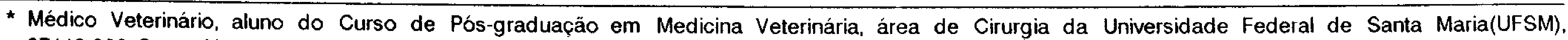
97119-900 Santa Maria, RS.

** Médico Veterinário. Professor Adjunto do Departamento de Clínica de Pequenos Animais da UFSM.
} 
do carpo em cães com neurectomia do radial. Os pinos transfixados foram estabilizados com acrílico autopolimerizável. Concluiram tratar-se de método eficiente e de baixo custo.

Visando contribuir ao estudo da imobilização de fraturas distais do úmero, são apresentados cinco casos onde 0 artifício imobilizador incluiu a imobilização temporária ou definitiva do cotovelo.

\section{MATERIAL E MÉTODO}

No hospital de Clínicas Veterinárias da Universidade Federal de Santa Maria foi feita redução e imobilizaçāo de fraturas distais do úmero em cinco cães, por meio de transfixaçāo óssea com pinos de Steinmann

Cão no 1

Cocker Spaniel, macho, 12 meses, 13,8kg. Sofreu acidente por automóvel. A radiografia revelou fratura intercondílea (em $Y$ ) da porçào distal do úmero esquerdo com liberação de esquírola óssea.

\section{Cão no 2}

Pinscher, fêmea, 6 meses, 1,0kg. Sofreu queda em escada. A fratura fora reduzida e imobilizada há 15 dias com um pino intramedular que transfixava também - clecrano. A radiografia evidenciou fratura distal do úmero esquerdo com migraçāo do implante $e$ osteomielite. Foi feita colheita de material para cultura e antibiograma.

Cāo no 3

Boxer, macho, 3 meses, 11,0kg. Paciente de atropelamento por automóvel. $\mathrm{O}$ exame radiográfico revelou fratura distal bilateral do úmero, epicondílea no membro direito e com fragmentação no esquerdo. (Figura 1).

\section{Cão no 4}

Dachshund, macho, 10 meses, $12,6 \mathrm{~kg}$. Atropelado por automóvel. $\mathrm{O}$ exame radiográfico demonstrou fratura epicondílea do úmero direito.

Cão no 5

Sem raça definida, macho, 18 meses, $17,8 \mathrm{~kg}$. Sofreu ferimento por arma de fogo (projétil calibre 32) no membro anterior direito. A radiografia indicou fratura distal oblíqua com liberação de esquírola no segmento proximal.

Em todos os cães o pré-operatório constou de jejum de 12 horas e tricotomia em toda região do braço e antebraço imediatamente antes da operação. A medicaçāo pré-anestésica foi feita com maleato de acepromazina ${ }^{2}(0,2 \mathrm{mg} / \mathrm{kg}$, via venosa) e a anestesia induzida e mantida com tiopental sódico $o^{b}$.

A área operatória foi submetida a antissepsia com álcool-iodo-álcool e delimitada por panos de campo esterilizados.

No Cocker Spaniel, Boxer, Dachshund e no cāo sem raça definida foi efetuada administração profilática de ampicilina sódica $(20 \mathrm{mg} / \mathrm{kg})$, vinte minutos antes da cirurgia. No Pinscher foi realizada antibioticoterapia com gentamicina $(4 \mathrm{mg} / \mathrm{kg})$ até desaparecerem os sinais de infecção.

O trans-operatório constou de abordagem pela face medial do úmero, em quatro cães, estendendo-se do terço médio até os côndilos para obter reduçāo da fratura devido ao cavalgamento dos segmentos fraturados. Após redução foi feita fixaçāo temporária com pinças ósseas de encaixe fixo para manter o alinhamento ósseo.

A seguir foram transfixados dois pinos de Steinmann, no segmento proximal à fratura do úmero e dois no terço proximal do rádio e ulna, com auxilio de um perfurador manual de Jacob. Os pinos foram introduzidos em sentido craneo-caudal, numa angulação aproximada de $45^{\circ} \mathrm{com}$ o osso. Após foram retorcidos em ângulo de $90^{\circ}$ (Figura 2a) em direção à linha de fratura e estabilizados com duas barras de acrílico ${ }^{c}$. Estas foram preparadas pela homogenização das frações pó e líquido e moldadas com a mão em torno dos pinos, até que a liga não permitisse mais sua manipulação. Aguardou-se 5 a 10 minutos, período em que ocorria a reação exotérmica devido a polimerização, para remoção das pinças ósseas que conferiam imobilização temporária da fratura.

No Pinscher foi feita curetagem da área infectada, lavagem exaustiva com soluçăo salina isotônica e adaptação de dreno. A síntese dos planos abordados foi feita com mononailon 4-0, neste caso, e 3-0 nos demais. No membro direito do Boxer (Figura 2b) e no Dachshund a transfixação foi percutânea (método fechado) pois as fraturas não apresentavam cavalgamento.

A retirada do aparelho de fixação foi feita por secção dos pinos com auxílio de alicate, entre as barras de acrílico e pele, a cada lado do membro e tração sobre as porções remanescentes.

\section{RESULTADOS E DISCUSSÃO}

O exame bacteriológico do material colhido do foco de fratura do Pinscher revelou a presença de 
Proteus sp sensível à gentamicina e cefazolina e Escherichia coli sensível à gentamicina, neomicina e nitrofurantoína. O esquema terapêutico com gentamicina parenteral durante 10 dias, associado a lavagem da ferida através do dreno, com povidine degermante diluído 1:1000 em solução salina isotônica de cloreto de sódio foi suficiente para debelar à infecção. A esclerose e desvitalização óssea resultante da infecção dificulta o aporte sangüineo do antibiótico, administrado por via sistêmica, ao foco infeccioso. A associação do antibiótico parenteral com um bactericida tópico como o iodo, na diluição utilizada, não irrita os tecidos e assegura eficiência terapêutica. É claro que a debridação e curetagem são essenciais para remover tecidos desvitalizados que acompanham esses casos. Nos outros cães a administração profilática da ampicilina visou proteção contra possíveis contaminações durante $\mathrm{o}$ ato operatório.

Em todos os cães o método de transfixação ofereceu adequada estabilização da fratura, constituindo-se em opção para substituir as placas. e parafusos, aliando-se a eficiência, simplicidade, resistência e baixo custo citados por BERTOL \& GOUVEIA SOBRINHO (1978) e GRUMADAS \& RAISER (1988). Apesar da rígida imobilização que este artifício oferece, permitindo a utilização precoce do membro, previne a movimentação articular o que não ocorre com a adaptação de placas de compressão dinâmica

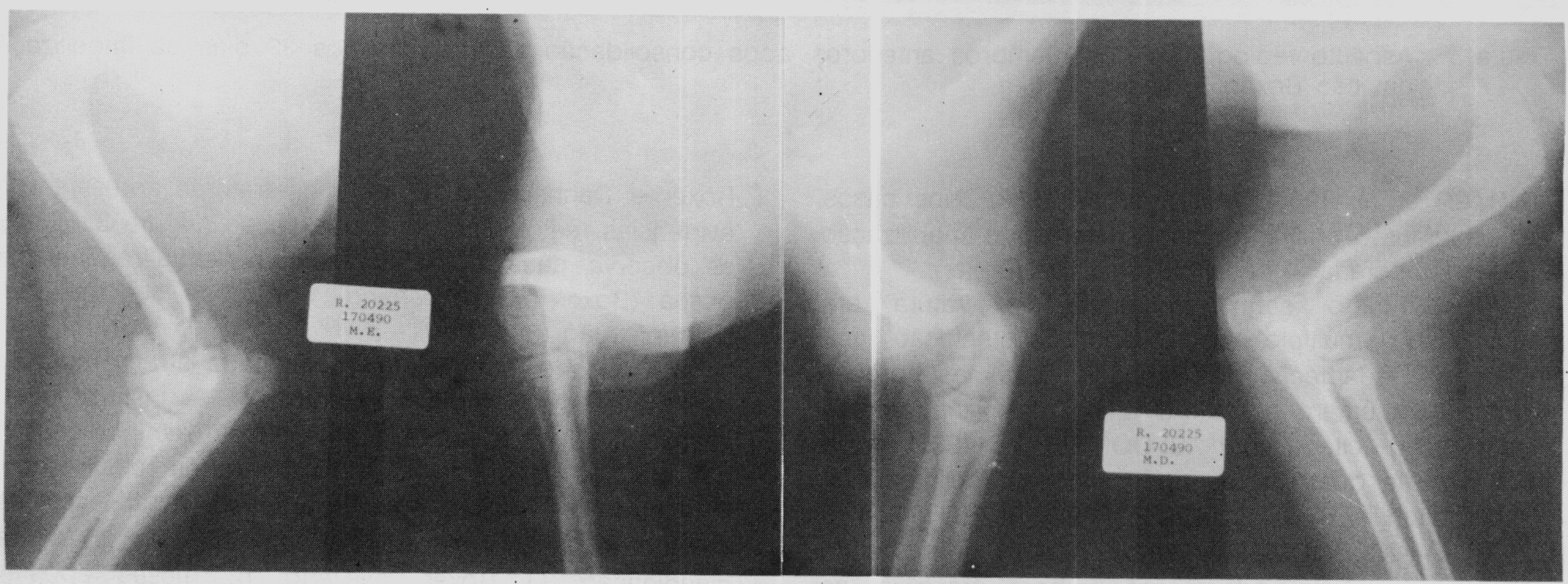

Figura I - Aspecto radiográfico das fraturas de úmero direito e esquerdo do cão Boxer, 3 meses, 11,0kg

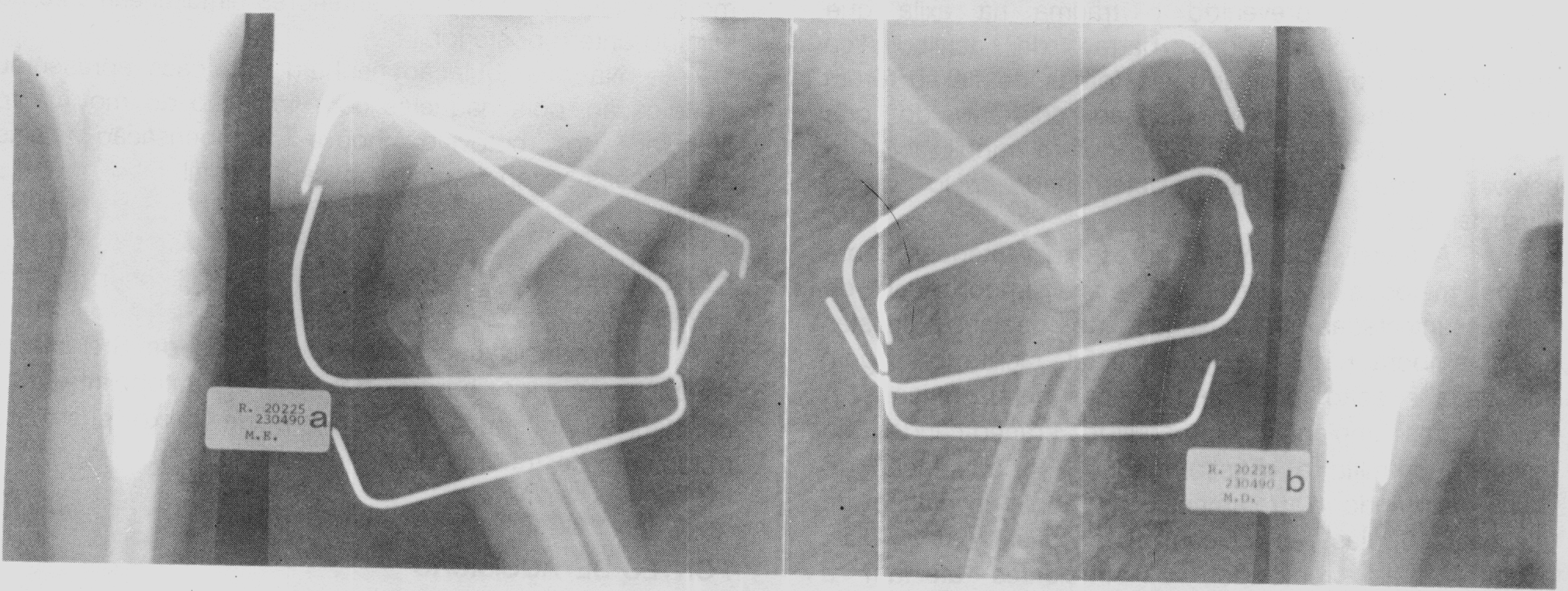

Figura 2a/b - Aspecto radiográfico das fraturas de úmero direito e esquerdo, após redução e imobilização por transtixação esquelética em cão Boxer, 3 meses, 11,0kg 


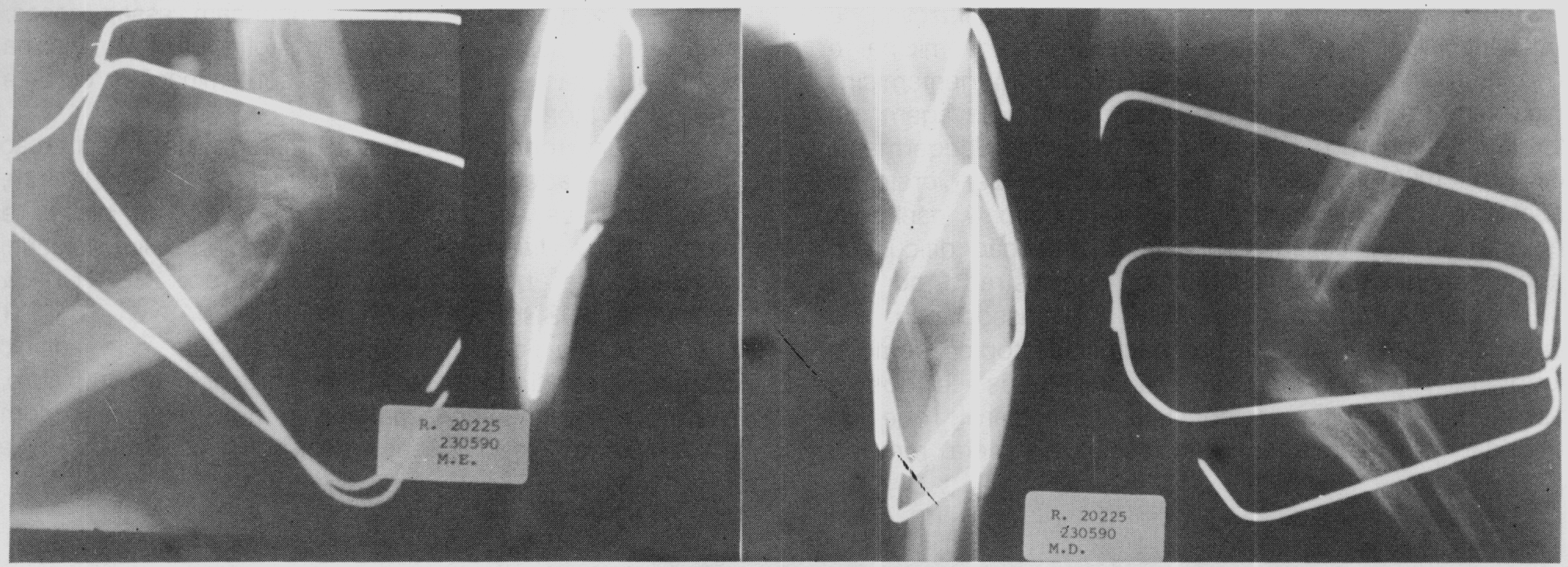

Figura 3 - Aspecto radiográfico dos membros anteriores, após consolidação das fraturas aos 32 dias de imobilização em cão Boxer, 3 meses, 11,0kg.

(BRINKER et al, 1986; VANINI et al, 1988). Nos casos aqui relatados o artifício utilizado determinou imobilização articular temporária (4 cães) ou definitiva (Boxer).

Como o segmento distal da fratura era pequeno ou múltiplo, não dando sustentação aos implantes, a adaptação dos pinos foi feita nas porções proximais do úmero e rádio-ulna. A transfixação seguiu a angulação citada por BLOOMBERG (1986) e a adaptação de duas barras de acrílico autopolimerizável, como fizeram BERTOL \& GOUVEIA SOBRINHO (1978) e BJORLING \& TOOMBS (1982), porém em sentido crâneo-caudal. Esta orientação, embora transfixe os músculos bíceps e tríceps braquial, não causou comprometimento dos mesmos pois a imobilização do cotovelo evitou a ação flexora ou extensora. Paralelamente foi prevenido o trauma na axila que ocorre quando uma das barras de acrílico fica medialmente. Por outro lado, as forças de flexão foram adequadamente antagonizadas, ao contrário do que observaram EGGER et al, (1983), pois a imobilização do cotovelo evita 0 estresse determinado pelo grupo muscular flexor.

A transfixação óssea apresenta vantagens sobre outros métodos de osteosíntese na imobilização de fraturas infectadas. A ausência de implantes nestas áreas, embora não seja fundamental. facilita drenagem adequada e ação local de fármacos antibacterianos. A fixação dos implantes em sentido craneo-caudal, no Pinscher, permitiu o acesso medial e a adaptação do dreno facilitando o tratamento. A rápida involução da infecção (10 dias) e a cicatrização óssea em 45 dias, quando foram removidos os implantes atestam a eficiência do método. Os implantes foram removidos nesta data, também no Cocker Spaniel e no cão sem raça definida e aos 32 e 35 dias respectivamente no
Boxer e Dachschund, quando as fraturas apresentavam evidências radiológica de consolidação (Figura 3). Como se observa, cães jovens apresentam rápida regeneração óssea (Boxer e Dachschund) que pode ser retardada pela infecção (Pinscher).

Nos cinco cães foi constatada atrofia muscular devido a imobilização do cotovelo. A instituição de exercícios ativos (deambulação) permitiu recuperação em período que variou de 40 a 70 dias após remoção dos implantes. O Cocker Spaniel apresentou limitação em $45^{\circ}$ da extensão e flexão do cotovelo, sem evidenciar claudicação. O Boxer, avaliado 12 meses após a remoção dos implantes, ainda apresentava rigidez articular mais acentuada no lado esquerdo, configurando ocorrência de artrodese. Durante a corrida este animal movimentava os membros anteriores simultaneamente no sentido ântero-posterior.

$\mathrm{Na}$ deambulação nenhum dos cães apresentou claudicação, pois naqueles com limitação do movimento articular do cotovelo houve compensação pelas articulações escápulo-umeral e carpo-radial.

\section{CONCLUSÃO}

A transfixação óssea com pinos de Steinmann, estabilizados por barras de acrílico autopolimerizável constitui-se em opção eficiente e de baixo custo no tratamento de fraturas distais do úmeró.

\section{FONTES DE AQUISIÇÃO}

a - Acepran 1\%: Univet S.A.- Rua Clímaco Barbosa, 700 - São Paulo, SP. 
b - Thionembutal: Abbott Lab. do Brasil Ltda. Rua Nova Korque, 245, São Paulo, SP.

c - JET Acrilico autopolimerizante: Artigos Odontológicos Clássicos Ltda. Av. Diógenes Ribeiro de Lima, 2720, São Paulo, SP.

\section{REFERÊNCIAS BIBLIOGRÁFICAS}

BERTOL, P., GOUVEIA SOBRINHO, J.L.F. O uso do fixador externo. Revista Brasileira de Ortopedia, v. 13, n.4, p. 155-158, 1978.

BJORLING, D.E., TOOMBS, J.P. Transarticular application of the Kirschner-Ehmer splint. Veterinary Surgery, $v$. 11, n. 1, p. 34-38, 1982.

BRINKER, W.O., PIERMATTEI, D.L., FLO, G.L. Manual de ortopedia $\theta$ tratamento das fraturas dos pequenos animais. São Paulo: Manole, 1986. Fraturas do úmero: p. $114-160$.
BLOOMBERG, M.S., Fraturas do rádio e ulna, In: BOJRAB, M.J. Cirurgia dos pequenos animais. 2. ed. São Paulo: Rocca, 1986. p. 749-766.

EGGER, E.L. Statistic strenght evaluation of six external skeletal fixation configurations. Veterinary surgery, $v$. 12, n. 3, p. 130-136, 1986.

GRUMADAS, C.E.S., RAISER, A.G. Correção de instabilidade articular experimental do carpo através de panartrodese obtida com aparelho de fixação externa com barras de acrílico. Revista Centro de Ciencias Rurais, v. 18, n. 1, p. 47-58, 1988.

SILVA, A.M., FIALHO, S.A.G., MACHADO, M.A., et al. Fixaçāo interna por compressão interfragmentária de osteotomias do côndilo lateral do fêmur e do úmero em cães. Arquivo Brasileiro de Medicina Veterinária e Zootecnia, v. 42, n. 42, n. 6, p. 465-476, 1990.

VANINNI,R., SMEAK, D.D., OLMSTEAD,M.L. Evaluation of surgical repair of 135 distal humeral fractures in dogs and cats. Journal of the American Animal Hospital Association, v. 24, p. 537-545, 1988. 